\title{
Yeni Bir Sezgisel Yöntem ile Tek Blok Tek Koridor Depo Yerleştirme Probleminin Çözümü
}

\section{The Solution of One-block One-Aisle Storage Allocation Problem by a New Heuristic} Method

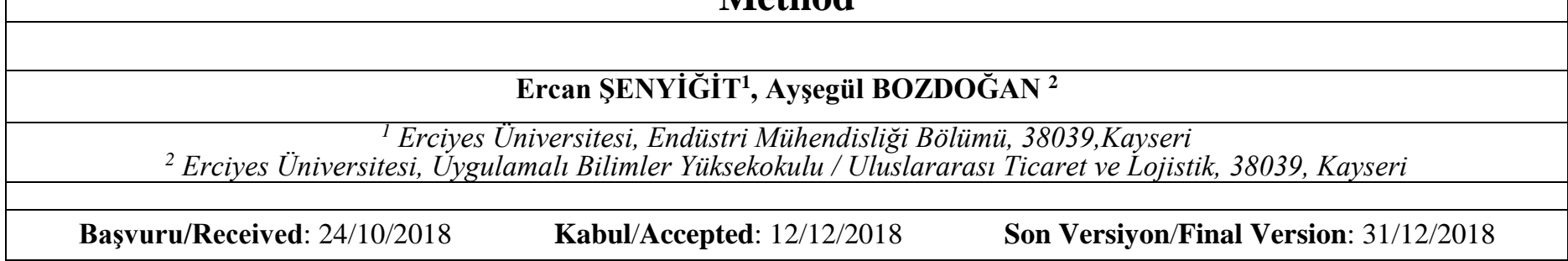

Öz

İnternet üzerinden yapılan toplam alışveriş tutarı her yıl artmaktadır. İnternet üzerinden ticaretin artması ile daha küçük miktarlarda daha fazla çeşitte ürün sipariş etme talebi ön plana çıkmaktadır. Bu durum, literatürde müşsteri odaklı sipariş verme olarak adlandırılmaktadır. İnternet üzerinden ticaret yapan firmaların rekabette yarışabilmelerinin en temel yeterliliği ise etkin depo yönetiminin sağlanmasıdır. Bu nedenle şirketler depo yönetimine gittikçe daha fazla önem vermektedir. Bu çalışmada müşteri odaklı sipariş toplama yapılan tek blok tek koridor depo yerleştirme problemi çözümünde yeni bir sezgisel yöntem sunulmuştur. Geliştirilen sezgisel yöntem sipariş ve öğelerin benzerliklerini dikkate almaktadır. Bu yeni sezgisel yöntem literatürde var olan veri seti kullanılarak daha önceden geliştirilmiş olan sipariş öğe miktarı yöntemi çözümü ve önceki çalışmadan farklı olarak herhangi bir yönteme dayanmayan rastgele belirlenen bir çözüm ile karşlaş̧ırılmıştır. Karşılaştırma sonucunda, dikkate alınan veriye göre yeni geliştirilen sezgisel yöntemin daha kısa toplama mesafesinde çözüm bulduğu belirlenmiştir.

\section{Anahtar Kelimeler}

"Depo yönetimi, atama problemi, depo yerleştirme problemi, sezgisel yöntem, öğeler arası benzerlik."

\begin{abstract}
The total amount of shopping on the internet is increasing every year. The demand for ordering more variety of products in smaller quantities with the increase of the trade on the internet comes to the forefront. This is referred to in the literature as customerfocused ordering. The most basic competence of companies that trade online is to provide efficient warehouse management. For this reason, companies are increasingly paying more attention to warehouse management. In this study, a new heuristic method has been presented to solve the problem of one block one aisle storage allocation with customer-focused ordering. This new heuristic method has been compared with the previously developed Order Item Quantity method solution and unlike previous work, a random solution using the existing data set in the literature. As a result of the comparison, it was determined that the newly developed heuristic method, based on the consideration given, found a solution at a shorter picking distance.
\end{abstract}

\section{Key Words}

"Warehouse management, assignment problem, storage allocation problem, heuristic, order item association." 


\section{GİRIŞ}

Depolama operasyonları arasında, sipariş toplama operasyonun literatürde en önemli operasyon olduğu belirtilmiştir (Liu, 1999). Gelişen bilgi sistemlerinin kullanımı rekabeti üst seviyelere çıkarmıştır. İnternet üzerinden alışveriş buna örnek olarak verilebilir. İnternet üzerinden alışveriş imkânı sağlayan modern perakende sistemleri yüksek stok devir hızı gerektirir, hızlı ve doğru bir ikmal sistemi temeline dayanmaktadır. İnternet üzerinden yapılan toplam alışveriş tutarı her yıl artmaktadır. İnternet üzerinden ticaret yapan firmaların rekabette yarışabilmelerinin en temel yeterliliği ise etkin depo yönetiminin sağlanmasıdır (Chuang ve arkadaşları, 2012; Şenyiğit ve Bozdoğan, 2018). Etkin depo yönetimine sahip firmalar internet üzerinden gelen siparişleri doğru ve zamanında sağlayabilmelidir. Bu nedenle şirketler, özellikle internet üzerinden satış yapan şirketler, depo yönetimine gittikçe daha fazla önem vermektedir. Çünkü zamanında ve doğru bir şekilde müşteri siparişleri müşterilere gönderilemez ise müşteri kayıpları yaşanabilir ve işletme zarar edebilir. Bunun olmaması için etkin bir depo yönetimine ihtiyaç bulunmaktadır. Elektronik sipariş verme sistemleri, perakendecilerin daha sık sipariş verme eğiliminde olmalarına ve daha az miktarda sipariş içeren sipariş emri vermelerine neden olmuştur (Örneğin ilaç depoları gibi).

Günümüzde müşterilerin verdiği siparişler, genellikle çok sayıda çeşitli öğe içermekte, fakat miktar olarak az sayıda olmaktadır. Bu durum toplam taşıma mesafesini arttırır. Bu sonuca adapte olmak için işletmeler sıkı bir rekabete girmişlerdir. Rekabet, depo yönetimini daha hayati öneme sahip bir role sokmuştur. Bu nedenle işletmeler depo yönetimi kararlarını en iyilemek zorunda kalmışlardır. Depo yönetiminde temel göstergelerden biri müşteri siparişlerini hazırlarken gidilen toplam taşıma mesafesini en aza indirmektir. Burada ele alınan problem, küçük parti büyüklükleri, çeşitlendirilmiş içerikler ve kısa tepki süreleri ile siparişlerle karşı karşıya olan, mevcut sipariş bazında bir deponun yerleştirme problemidir.

Bu çalışma, Şenyiğit ve Bozdoğan tarafından tek blok tek koridora sahip bir depoda müşteri odaklı (çok öğeli az miktarlı) sipariş toplama probleminin çözümü için sunulmuş olan sezgisel yaklaşımı (Şenyiğit ve Bozdoğan, 2018) rastgele elde edilen bir çözüm ile karşılaştırmaktadır. Doğru bir karşılaştırma yapabilmek için aynı veriler kullanılmıştır. Tek blok tek koridora sahip bir depo örneği şekil-1'de gösterilmiştir. Şekil incelendiğinde, şeklin ortasında bir koridor olduğu görülmekte ve bu koridorun her iki tarafında da depo rafları bulunmaktadır. Bu raflarda öğeler (hammadde, yarı mamul, ürün vb.) depolanmaktadır.

Literatürde, bu durum öğelerin benzerliklerine göre gruplandırılması olarak adlandırılmaktadır. Geleneksel olarak aile gruplama popüler olan kesikli p-medyan problemine dayanmaktadır. Liu (1999) çalışmasında kesikli p-medyan problemini sunmuştur. Lin ve Lu (1999) çalışmalarında iki aşamalı sipariş toplama sezgisel yöntemi geliştirmişlerdir. Liu (2004) çalışmasında, sipariş toplama probleminde hacim tabanlı bir politikanın üstünlüğünü, toplama mesafesini düşürürken kanıtlamıştır. De Koster ve arkadaşları (2007) öğeler arasındaki benzerlikleri dikkate alarak aile gruplama fikrini geliştirmiştir. Chuang ve arkadaşları (2012) özelleştirilmiş sipariş toplama problemi için iki aşamalı Kümeleme-Atama Problemi Modeli (CAPM) önermiş̧lerdir (Şenyiğit ve Bozdoğan, 2018).

Diaz (2016) çalışmasında müşteri talep kalıplarını ve sipariş kümelemesini dikkate alan bir yerleşim çözümü oluşturmak için kuadratik bir tam sayı programlama temelli bir sezgisel en iyileme yöntemi kullanmıştır. Li ve arkadaşları (2017) çalışmalarında, çoğunlukla hızlı hareket eden tüketim mallarına odaklanan Çin'in ünlü ve tipik bir online perakendecisine dayanan sipariş toplama miktarının ve toplayıcı rota mesafesinin en aza indirmesinin eşzamanlı en iyilemesini gerçekleştirmişlerdir. Dijkstra ve Roodbergen (2017) çalışmalarında yönlendirme yöntemlerinin ve depolama konumu atamasının işlem performansına birleşik etkilerine odaklanmışlardır. Accorsi ve arkadaşları (2018) çalışmalarında hem hassas hem de stok güvenliği hedeflerini karşılıklı olarak yönetmeyi sağlayan, sıcaklığa duyarlı ürünler için geliştirilmiş orijinal bir depo atama ilkesi önermişlerdir. Şenyiğit ve Bozdoğan (2018) çalışmalarında tek blok tek koridor depo yerleştirme problemi için yeni bir sezgisel yöntem önermişlerdir ve bir örnek üzerinden sipariş öğe miktarı yöntemi ile geliştirilen sezgisel yöntemin karşılaştırmasını yapmışlardır. Bu çalışma, Şenyiğit ve Bozdoğan (2018) çalışmasının, rastgele elde edilen bir çözüm ile karşılaştırmasını da içeren genişletilmiş halidir.

Literatürde, tek blok tek koridor depo yerleştirme problemi çalışılmış bir problemdir. Bu problem türünde temel performans kriteri müşteri siparişlerini hazırlarken gidilen toplam taşıma mesafesini en aza indirmektir. Bu problemin çözümü için farklı yöntemler geliştirilmiştir. Bu yöntemlere örnek olarak sipariş öğe miktarı yöntemi örnek olarak verilebilir. Bu çalışmada müşteri odaklı sipariş toplama yapılan tek blok tek koridor depo yerleştirme problemi çözümünde yeni bir sezgisel yöntem sunulmuştur. Geliştirilen sezgisel yöntem sipariş ve öğelerin benzerliklerini dikkate almaktadır. Bu yeni sezgisel yöntem, literatürde var olan veri seti kullanılarak daha önceden geliştirilmiş olan sipariş öğe miktarı yöntemi çözümü ile siparişlerini hazırlarken gidilen toplam taşıma mesafesi performans kriterine göre karşılaştırılmıştır.

Karş1laştırma sonucunda, dikkate alınan veriye göre yeni geliştirilen sezgisel yöntemin daha kısa toplama mesafesinde çözüm bulduğu belirlenmiştir. Bu çalışmanın amacı yeni geliştirilen sezgisel yöntemi tanıtmaktır. Şenyiğit ve Bozdoğan’ın önceki çalışmasında elde edilen sonuçları rastgele elde edilen bir çözüm ile karşılaştırmaktır. 


\section{Terminoloji}
P (i) Öğe i için sipariș sayısı
$P(j) \quad$ Öğe j için sipariş sayısı
$\mathrm{S} \quad$ Sipariş
$\mathrm{S}_{\mathrm{ij}} \quad$ Öğe indeksi; $\mathrm{i}$ ve $\mathrm{j}$ arasındaki indeks
I/O Başlangıç Konumu
$\mathrm{d}_{1} \quad$ Depolama birimi 1 'nin başlangıç konumuna (I / O) olan mesafesi

\section{MATERYAL VE YÖNTEM}

Literatürde tek blok tek koridor depo yerleştirme problemi çözümü için değişik yöntemler geliştirilmiştir. Bu çalışmada bu yöntemlere yeni bir alternatif sunulmasına çalıșılmıștır. Problemin anlaşılabilmesi ve karşılaştırmanın sadeliği için çalıșmada tek örnek dikkate alınmıştır. Tablo 1'de örnek veri gösterilmiştir. Bir sonraki bölümde çalışmada dikkate alınan varsayımlar belirtilmiştir.

\subsection{Varsayımlar}

Çalışmada dikkate alınan depo, tek bloklu ve tek koridorludur. Depolama alanı ayarlanabilmektedir. Stoklanan ürünlerin boyutlarının ihmal edildiği varsayılmıştır. Depo içerisinde depolama birimlerinin aynı boyutlarda olduğu kabul edilmiştir. Depo birimleri özdeştir. Depo içerisinde siparişi toplama yolu $Z$ harfi şeklinde hareket yolu kullanılarak tasarlandığı kabul edilmiştir. $Z$ harfi şeklindeki harekette dikey ve yatay birim mesafeler özdeştir ve bir birimdir. Alınan siparişte çok çeşitli öğeler olduğu ve miktarının da çeşitli olduğu kabul edilmiştir. Sipariş toplama işlemine başlangıç konumundan başlanıp (Şekil 1) siparişler tamamlandığında tekrar geri başlangıç konumuna dönüldüğü kabul edilmiştir.

Performans kriteri, böyle bir depo sisteminde siparişi hazırlama toplama mesafesini en aza indirmek olarak belirlenmiştir. Sipariş öğe miktarı yöntemi ve önerilen sezgisel yaklaşımın anlatımı bir örnek (Tablo 1) üzerinden yapılmaktadır. Tablo 1 incelendiğinde toplam 10 farklı sipariş olduğu görülmektedir. Bu siparişlerin her birinin farklı sayıda öğeleri olduğu görülmektedir. Her bir öğeye ait toplam öğe tekrar sayısı ve sipariş tekrar sayıları verilmiştir (Tablo 1). Her bir siparişin içerdiği siparişteki öğe sayısı miktarı ve her bir siparişin içerdiği farklı öğe sayısı tablo 1'de gösterilmiştir.

Tablo 1. Örnek veri (Chuang ve arkadaşları, 2012;Şenyiğit ve Bozdoğan, 2018)

\begin{tabular}{|c|c|c|c|c|c|c|c|c|c|c|}
\hline \multirow[b]{2}{*}{ Siparişler } & \multicolumn{8}{|c|}{ Ö̆ğeler } & \multirow[b]{2}{*}{ Siparişteki Öğe Miktarı } & \multirow[b]{2}{*}{ Farklı Öğe Sayısı } \\
\hline & 1 & 2 & 3 & 4 & 5 & 6 & 7 & 8 & & \\
\hline S1 & 5 & 4 & 3 & 2 & & & & & 14 & 4 \\
\hline $\mathbf{S 2}$ & 2 & 1 & 2 & & & & & & 5 & 3 \\
\hline S3 & 1 & 5 & & 3 & & & & & 9 & 3 \\
\hline S4 & 3 & & 1 & 5 & & & & & 9 & 3 \\
\hline S5 & & & & 4 & 1 & 3 & 5 & 1 & 14 & 5 \\
\hline S6 & & & & & 2 & & 4 & 2 & 8 & 3 \\
\hline S7 & 9 & & 2 & 5 & & & & & 16 & 3 \\
\hline S8 & 4 & 3 & & 4 & 5 & & & & 16 & 4 \\
\hline S9 & & & & & & 5 & 3 & 6 & 14 & 3 \\
\hline S10 & 7 & & & 2 & 6 & 4 & & & 19 & 4 \\
\hline Toplam öğe sayısı & 31 & 13 & 8 & 25 & 14 & 12 & 12 & 9 & 124 & \\
\hline Öğe tekrarlanma sayısı & 7 & 4 & 4 & 7 & 4 & 3 & 3 & 3 & & 35 \\
\hline
\end{tabular}

\subsection{Yeni sezgisel yaklaşım}

Geliştirilen bu yeni sezgisel yaklaşım 5 adımdan oluşmaktadır. Bu adımlar aşağıda belirtilmiştir.

1.Adım: Öğeler arasındaki ilişki (öğe indeks değerleri) hesaplanır.

2.Adım: Öğeler, öğeler arasındaki öğe indeks değerlerine göre gruplara ayrılır.

3.Adım: Gruplar için depolama sırası belirlenir.

4.Adım: En küçük öğe numarası ilk, en büyük öğe sayısı son olacak şekilde öğeler için depolama sırası belirlenir.

5.Adım: Toplam taşıma mesafesi hesaplanır. 
Yeni yaklaşımın ilk adımında denklem-1'de gösterilen denklem ile öğe indeks değeri hesaplanır (Şenyiğit ve Bozdoğan, 2018). Hesaplanan katsayı, öğe indeks değeri olarak adlandırılır. Denklem-1'deki $P(i \cap j)$ ifadesi, hem $i$ siparişi hem de $j$ siparişindeki ortak öğe sayısını ifade etmektedir.

$$
S_{i j}=1-\frac{P(i \cap j)}{[P(i)+P(j)]}
$$

Tablo 2'de denklem-1 kullanılarak elde edilen öğe indeks değerleri gösterilmiştir. Öğe indeks değeri $O$ ile 1 arasında değer almaktadır. İki öğe arasında 0.5 öğe indeks değeri varsa bu $i$ ve $j$ öğelerinin her zaman birlikte sipariş edilmesi gerektiği anlamına gelmektedir. İki öğe arasında $l$ öğe indeks değeri varsa bu i ve j öğelerinin asla birlikte sipariş edilmemesi gerektiği anlamına gelmektedir.

Tablo 2'deki öğe indeks değerleri incelendiğinde sadece 7. ve 8. öğelerin her zaman birlikte sipariş edilmesi gerektiği ortaya çıkmıştır. 7 ile 8 nolu öğeler arasındaki öğe indeks değeri 0.5 'tir. 3 nolu öğe ile 5, 6, 7 ve 8 nolu öğelerin asla birlikte sipariş edilmemesi gerektiği ortaya çıkmıştır. Çünkü bunlar arasındaki öğe indeks değeri l'dir. 1 nolu öğe ile 2 ve 4 nolu öğelerin öğe indeks değerleri 0.6 'dır. 2 ile 4 nolu öğeler arasındaki öğe indeks değeri 0.6 'dır.

Tablo 2. Öğe indeks değerlerinin gösterilmesi (Şenyiğit ve Bozdoğan, 2018)

\begin{tabular}{ccccccccc}
\hline \multicolumn{1}{c}{ Öğe İndeks Değerleri } \\
\hline Öğgeler & $\mathbf{1}$ & $\mathbf{2}$ & $\mathbf{3}$ & $\mathbf{4}$ & $\mathbf{5}$ & $\mathbf{6}$ & $\mathbf{7}$ & $\mathbf{8}$ \\
\hline $\mathbf{1}$ & 0 & $\underline{\mathbf{0 . 6}}$ & 0.6 & $\underline{\mathbf{0 . 6}}$ & 0.8 & 0.9 & 1 & 1 \\
$\mathbf{2}$ & 0.6 & 0 & 0.7 & 0.6 & 0.9 & 1 & 1 & 1 \\
$\mathbf{3}$ & 0.6 & 0.7 & 0 & 0.7 & 1 & 1 & 1 & 1 \\
$\mathbf{4}$ & 0.6 & $\underline{\mathbf{0 . 6}}$ & 0.7 & 0 & 0.7 & 0.8 & 0.9 & 0.9 \\
$\mathbf{5}$ & 0.8 & 0.9 & 1 & 0.7 & 0 & 0.7 & 0.7 & 0.7 \\
$\mathbf{6}$ & 0.9 & 1 & 1 & 0.8 & 0.7 & 0 & 0.7 & 0.7 \\
$\mathbf{7}$ & 1 & 1 & 1 & 0.9 & 0.7 & 0.7 & 0 & $\underline{\mathbf{0 . 5}}$ \\
$\mathbf{8}$ & 1 & 1 & 1 & 0.9 & 0.7 & 0.7 & $\underline{\mathbf{0 . 5}}$ & 0 \\
\hline
\end{tabular}

Yeni sezgisel yaklaşımın ikinci adımında öğe indeks değerleri dikkate alınarak öğelerin gruplara ayrılması gerekmektedir. Bu değerlere göre 3, 5 ve 6 nolu öğeler ayrı birer grup olmalıdır. 1,2 ve 4 nolu öğeler beraber bir gruba ve son olarak 7 ile 8 nolu öğeler beraber bir grup oluşturmaktadır. Grup oluşturmalarında kriter, öğe indeks değerleridir.

Gruplar, öğe indeks değerlerine göre oluşturulmaktadır. Öğe indeks değeri 0 ile 1 arasında değer almaktadır. İki öğe arasında 0.5 öğe indeks değeri varsa bu $i$ ve $j$ öğelerinin her zaman birlikte sipariş edilmesi gerektiği anlamına gelmektedir. İki öğe arasında 1 öğe indeks değeri varsa bu $i$ ve $j$ öğelerinin asla birlikte sipariş edilmemesi gerektiği anlamına gelmektedir. Tablo 2 incelendiğinde $\underline{0.5}$ öğe indeks değerine sahip öğelerin 7 ve 8 nolu öğeler olduğu görülmektedir. Bu nedenle 7 ve 8 nolu öğeler bir grup oluşturmuştur. 0.6 öğe indeks değerine sahip 8 farklı değer tablo 2'de belirlenmiştir. Tablo 2'nin 1. Satırına bakalım. Bu sırada 1 nolu öğenin diğer öğeler ile birlikte öğe indeks değerleri gösterilmiştir. Bu değerlere göre, 1 ile 2,3 ve 4 nolu $(\underline{0.0})$ öğelerin beraber gruplanması gerekmektedir. 2,3 ve 4 nolu öğelerinin diğer öğeler ile birlikte öğe indeks değerleri dikkate alındığında 3 nolu öğenin 2 ve 4 nolu öğelerle birlikte öğe indeks değeri dikkate alındığında (0.7) daha yüksek olduğu görülmektedir. Bu nedenle 1,2 ve 4 nolu öğeler beraber gruplanmıştır. Geriye kalan 3, 5 ve 6 nolu öğelerin öğe indeks değerleri 1 olduğu için her biri ayrı bir grup olarak değerlendirilmiş ve tablo 3 ’te gösterilmiştir. Bu şekilde toplam 5 farklı grup belirlenmiştir.

Üçüncü adımda öğelerin depo içerisindeki sıralamalarının yerlerinin belirlenmesi gerekir. Yeni geliştirilen sezgisel yöntem, Tablo 3'te gösterilen gruplamaya göre depo içerisindeki sıralamanın oluşmasını öngörmektedir. Geliştirilen yeni sezgisel yöntemde sıralama, öğelerinin numaralarına göre yapılmaktadır. Geliştirilen yeni sezgisel yöntemde, numarası küçük olan öğelerin önceliği bulunduğu varsayılmıştır. Yeni geliştirilen sezgisel yöntem, tablo 1'deki örnek veriye göre geliştirilen çözümün toplam mesafesini hesaplar. Tablo 4'te ise yeni sezgisel yönteme göre öğelerin depo içerisinde sıralarının gösterilmesi yapılmıştır. Depo içerisinde siparişi toplama yolu $Z$ harfi şeklinde olacağı için 4 ve 3 nolu öğelerden sonra 5 ve 6 nolu öğeler gelecektir. $Z$ hareketi Şekil 1'de bu sıralama görsel olarak ifade edilmiştir. 
Tablo 3. Gruplar ve bu grupların öğelerinin gösterilmesi (Şenyiğit ve Bozdoğan, 2018)

\begin{tabular}{cc} 
Grup No & Öğeler \\
\hline 1 & $1,2,4$ \\
2 & 3 \\
3 & 5 \\
4 & 6 \\
5 & 7,8 \\
\hline
\end{tabular}

Tablo 4. Yeni sezgisel yönteme göre öğelerin depo içerisinde sıralarının gösterilmesi (Şenyiğit ve Bozdoğan, 2018)

\begin{tabular}{cc} 
Sıra No & Öğe No \\
\hline 1 & 1 \\
2 & 2 \\
3 & 4 \\
4 & 3 \\
5 & 5 \\
6 & 6 \\
7 & 7 \\
8 & 8 \\
\hline
\end{tabular}
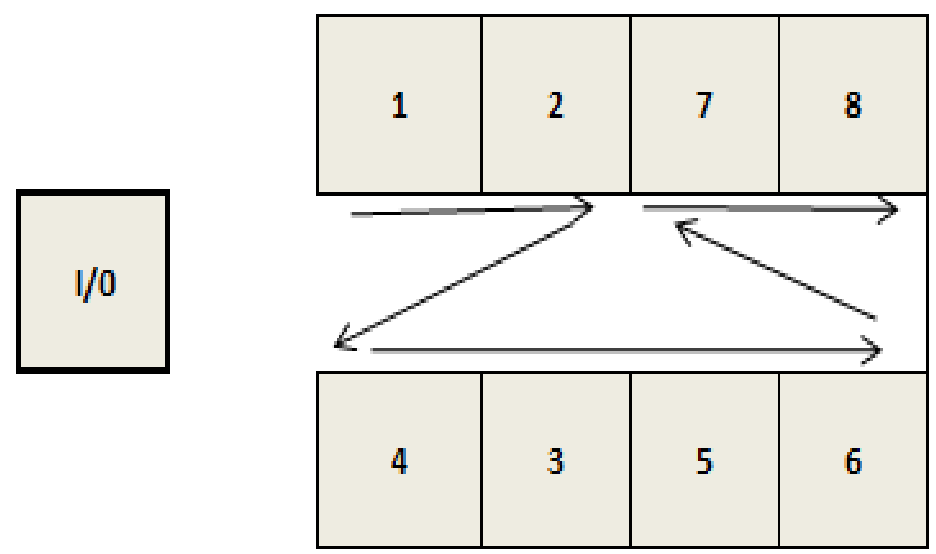

Şekil. 1. Yeni sezgisel yönteme göre depo içerisinde öğelerin sıralamasının gösterilmesi (Şenyiğit ve Bozdoğan, 2018)

4. adımda, en küçük öğe numarası ilk, en büyük öğe sayısı son olacak şekilde öğeler için depolama sırası belirlenir. Şekil-1'de bu sıralama görsel olarak gösterilmiştir. Son adım olarak da toplam taşıma mesafesi hesaplanır. Tablo-7'de 74 birim toplam taşıma mesafesi olduğu gösterilmiştir.

\subsection{Sipariş öğe miktarı yöntemi (Order Item Quantity)}

Sipariş ve öğe istatistiklerine dayanan bir depo yerleştirme yöntemidir. Bu yöntemin amacı çok tekrar edilen öğelerin girişe yakın yerlere yerleştirilmesini, az tekrar eden öğelerin ise girişe uzak yerlere yerleştirilmesini sağlamaktadır. Tablo 5'te sipariş öğe miktarı yönteminde kullanılan öğe tekrar istatistikleri gösterilmektedir (Şenyiğit ve Bozdoğan, 2018). Sipariş öğe miktarı yöntemine göre belirlenen öğelerin depo içerisinde sıraları Tablo 6'da gösterilmiştir. Şekil 2'de ise bu sıralama depo içerisinde nasıl olduğu gösterilmiştir (Şenyiğit ve Bozdoğan, 2018). 
Tablo 5. Sipariş öğe miktarı yönteminde kullanılan öğe tekrar istatistikleri (Şenyiğit ve Bozdoğan, 2018)

\begin{tabular}{cccc} 
Sıra & Ö̆̆ & Tekrar Sayısı & \% \\
\hline 1 & 1 & 7 & 0.20 \\
2 & 4 & 4 & 0.11 \\
3 & 5 & 4 & 0.11 \\
4 & 2 & 7 & 0.20 \\
5 & 3 & 4 & 0.11 \\
6 & 6 & 3 & 0.09 \\
7 & 7 & 3 & 0.09 \\
8 & 8 & 3 & 0.09 \\
\hline \multicolumn{2}{c}{ Toplam } & 35 & 1 \\
\hline
\end{tabular}

Tablo 6. Sipariş öğe miktarı yöntemine göre öğelerin depo içerisinde sıralarının gösterilmesi (Şenyiğit ve Bozdoğan, 2018)

\begin{tabular}{cc} 
Sıra No & Öğe No \\
\hline 1 & 1 \\
2 & 4 \\
3 & 5 \\
4 & 2 \\
5 & 3 \\
6 & 6 \\
7 & 7 \\
8 & 8 \\
\hline
\end{tabular}
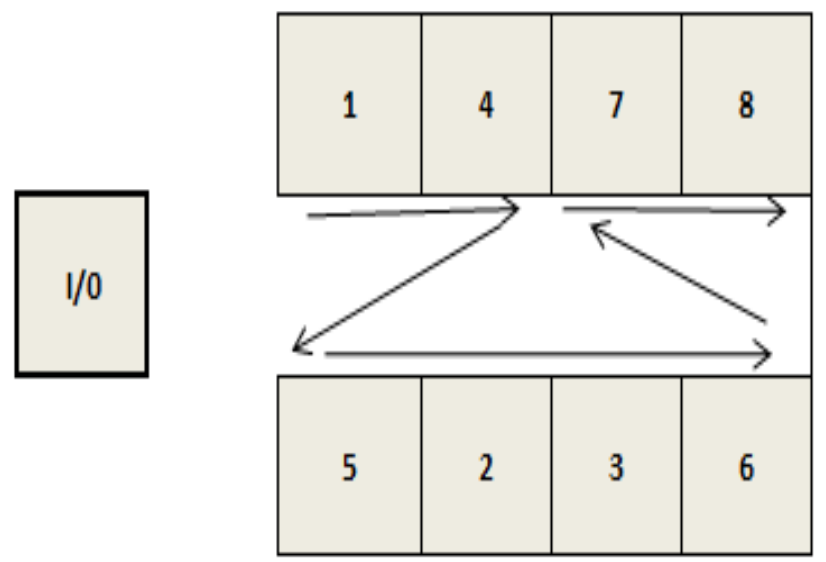

Şekil. 2. Sipariş Öğe Miktarı yöntemine göre depo içerisinde öğelerin sıralamasının gösterilmesi (Şenyiğit ve Bozdoğan, 2018)

\section{BULGULAR}

Bu bölümde çalışmada elde edilen bulgular açıklanacaktır. Önerilen yeni sezgisel yönteme göre belirlenen yerleşime göre siparişler toplanır toplam taşıma mesafesi hesaplanır (Tablo 7). Tablo 7'deki 1 nolu siparişi dikkate alalım. Bu siparişte 4 öğe toplanacaktır. Sıralama 1, 2, 3 ve 4 nolu öğelerin toplanması ile tamamlanacaktır. Başlangıçtan 1 nolu depo birimine gelmek için 1 birim mesafe kat edilecektir. 1 nolu depo biriminden 2 nolu depo birimine gelmek için 1 birim mesafe gidilecektir. Sirada 3 nolu öğenin toplanması bulunmaktadır. 3 nolu koridor karşı tarafta olduğu için $Z$ şeklindeki hareketten dolayı $l$ birim karşıya geçme mesafesi ve 4 nolu depo biriminden 3 nolu depo birimine ulaşmak için 1 birim mesafe olmak üzere toplam 2 birim mesafe gidilmesi gerekmektedir. 
Tablo 7. Yeni sezgisel yönteme göre çözümün gösterilmesi (Şenyiğit ve Bozdoğan, 2018)

Öğeler

\begin{tabular}{|c|c|c|c|c|c|c|c|c|c|c|c|}
\hline Siparişler & Siparişlerin Sırası & 1 & 2 & 3 & 4 & 5 & 6 & 7 & 8 & Bitiş & Mesafe \\
\hline S1 & $1,2,3,4$ & 1 & 1 & 2 & 1 & & & & & 1 & 6 \\
\hline S2 & $1,2,3$ & 1 & 1 & 2 & & & & & & 2 & 6 \\
\hline S3 & $1,2,4$ & 1 & 1 & & 1 & & & & & 1 & 4 \\
\hline E4 & $1,3,4$ & 1 & & 3 & 1 & & & & & 1 & 6 \\
\hline S5 & $4,5,6,7,8$ & & & & 1 & 2 & 1 & 1 & 1 & 4 & 10 \\
\hline S6 & $5,7,8$ & & & & & 3 & & 2 & 1 & 4 & 10 \\
\hline S7 & $1,3,4$ & 1 & & 3 & 1 & & & & & 1 & 6 \\
\hline S8 & $1,2,4,5$ & 1 & 1 & & 1 & 2 & & & & 3 & 8 \\
\hline S9 & $5,6,7$ & & & & & 3 & 1 & 1 & & 3 & 8 \\
\hline \multirow[t]{2}{*}{ S10 } & $1,4,5,6$ & 1 & & & 2 & 2 & 1 & & & 4 & 10 \\
\hline & & & & & & & & & & Toplam & 74 Birim \\
\hline
\end{tabular}

Tablo 8. Sipariş öğe miktarı yöntemine göre çözümünün gösterilmesi (Şenyiğit ve Bozdoğan, 2018)

\begin{tabular}{|c|c|c|c|c|c|c|c|c|c|c|c|}
\hline & \multicolumn{11}{|c|}{ Öğeler } \\
\hline Siparişler & Siparişlerin Sırası & 1 & 2 & 3 & 4 & 5 & 6 & 7 & 8 & Bitiş & Mesafe \\
\hline S1 & $1,2,3,4$ & 1 & 3 & 1 & 3 & & & & & 2 & 10 \\
\hline $\mathrm{S} 2$ & $1,2,3$ & 1 & 3 & 1 & & & & & & 3 & 8 \\
\hline S3 & $1,2,4$ & 1 & 3 & & 3 & & & & & 2 & 9 \\
\hline S4 & $1,3,4$ & 1 & & 6 & 3 & & & & & 2 & 12 \\
\hline S5 & $4,5,6,7,8$ & & & & 2 & 1 & 3 & 1 & 1 & 4 & 12 \\
\hline S6 & $5,7,8$ & & & & & 1 & & 4 & 1 & 4 & 10 \\
\hline S7 & $1,3,4$ & 1 & & 6 & 3 & & & & & 2 & 12 \\
\hline S8 & $1,2,4,5$ & 1 & 3 & & 3 & 1 & & & & 1 & 9 \\
\hline S9 & $5,6,7$ & & & & & 1 & 3 & 1 & & 3 & 8 \\
\hline $\mathrm{S} 10$ & $1,4,5,6$ & 1 & & & 1 & 1 & 3 & & & 4 & 10 \\
\hline
\end{tabular}

Çalışmada karşı koridora geçme mesafesinin 1 birim olduğu kabul edilmiştir. 3 ve 4 nolu depo birimleri yan yana oldukları için aralarındaki mesafe 1 birimdir. Böylece toplanması gereken öğeler tamamlanmıştır. Fakat başlangıç konumuna geri dönülmesi gerekmektedir. Bu nedenle, 4 nolu depo biriminden başlangıç konumuna gelinmesi için 1 birim daha mesafe gidilmesine ihtiyaç duyulmaktadır. Sonuç olarak bu siparişlerin toplanması için toplam 6 birim mesafe kat edilmiştir. Tablo 8'de sipariş öğe miktarı yöntemi kullanılarak elde edilen çözüm gösterilmiştir. Geliştirilen sezgisel yöntem ile sipariş öğe miktarı yöntemlerinin 
çözümleri karşılaştırmada kolaylık olsun diye alt alta konulmuştur (Bakınız, tablo-7 ve tablo-8). Çalışmada kullanılan ve literatürde var olan yöntemler dışında bu problemin çözümü rastgele bir şekilde de elde edilebilir. Bu çözümün performansının kötü olacağı açıktır. Bu durumu gösterebilmek için elde edilen rastgele bir çözüm aşağıda gösterilmiştir. Bu makale çalışmasının bildiri çalışmasından farkı rastgele elde edilen veriler kullanılarak sunulan çözümün gösterilmesidir.

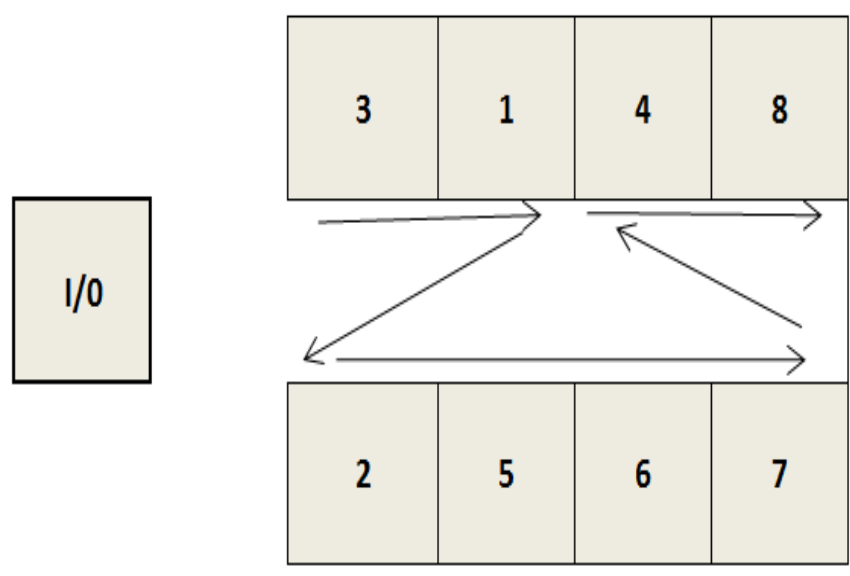

Şekil. 3. Rastgele bir şekilde belirlenen depo içerisinde öğelerin sıralamasının gösterilmesi

Tablo 9. Rastgele elde edilen çözümünün gösterilmesi

\begin{tabular}{|c|c|c|c|c|c|c|c|c|c|c|c|}
\hline & \multicolumn{11}{|c|}{ Ŏğeler } \\
\hline Siparișler & Siparişlerin Sırası & 1 & 2 & 3 & 4 & 5 & 6 & 7 & 8 & Bitiș & Mesafe \\
\hline S1 & $1,2,3,4$ & 2 & 1 & 2 & 6 & & & & & 2 & 14 \\
\hline $\mathrm{S} 2$ & $1,2,3$ & 2 & 1 & 2 & & & & & & 3 & 6 \\
\hline S3 & $1,2,4$ & 2 & 1 & & 4 & & & & & 2 & 10 \\
\hline S4 & $1,3,4$ & 2 & & 1 & 6 & & & & & 2 & 12 \\
\hline S5 & $4,5,6,7,8$ & & & & 3 & 2 & 1 & 1 & 2 & 4 & 13 \\
\hline S6 & $5,7,8$ & & & & & 2 & & 2 & 2 & 4 & 10 \\
\hline S7 & $1,3,4$ & 2 & & 1 & 6 & & & & & 2 & 12 \\
\hline S8 & $1,2,4,5$ & 2 & 1 & & 4 & 2 & & & & 1 & 11 \\
\hline S9 & $5,6,7$ & & & & & 2 & 1 & 1 & & 3 & 8 \\
\hline $\mathrm{S} 10$ & $1,4,5,6$ & 2 & & & 5 & 2 & 1 & & & 4 & 13 \\
\hline
\end{tabular}

Şekil 3 'te rastgele belirlenen depo içerisinde öğelerin sıralamasının yerleşimi şekilsel gösterimi yapılmıştır. Depo içerisinde şekil 3 'te gösterildiği gibi yerleştirilen öğelerin, verilen siparişlere göre ve siparişlerin sırasına göre toplanması sırasında kat edilen mesafeler tablo 9'da gösterilmiştir. Buna göre toplam mesafe 109 birim olarak bulunmuştur.

\section{SONUÇLAR}

$\mathrm{Bu}$ çalışmada ele alınan problemin çözümü için Şenyiğit ve Bozdoğan tarafından yeni bir sezgisel yöntem geliştirilmiştir. Bu geliştirilen yöntem literatürdeki veri seti kullanılarak sipariş öğe miktarı yöntemi ile karşılaştırılmıştır. Bu yeni çalışmada ise sonuçlar rastgele belirlenen bir çözüm ile karşılaştırılmıştır. Tablo 7'de yeni sezgisel yöntem kullanılarak elde edilen çözüm, Tablo 8'de ise sipariş öğe miktarı yöntemi kullanılarak ve Tablo 9'da ise rastgele elde edilen çözüm gösterilmiştir. Yeni geliştirilen sezgisel yöntem 74 birim toplama mesafesine sahip iken, sipariş öğe miktarı yöntemi 100 birim toplama mesafesine ve son olarak rastgele belirlenen çözüm ise 109 birim toplama mesafesine sahiptir. Bu örnek veriye göre geliştirilen yeni sezgisel yöntem sipariş öğe miktarı yöntemine ve rastgele belirlenen çözüme göre daha kısa toplama mesafesinde çözüme ulaşmıştır. Bu 
çalışma ile Şenyiğit ve Bozdoğan tarafından geliştirilen sezgisel yöntemin tanıtımı yapılmış, aynı örnek üzerinden sezgisel yöntemin performansının daha iyi olduğu gösterebilmek için sipariş öğe miktarı yöntemi ve rastgele elde edilen çözüm ile karşılaştırması yapılmıştır.

$\mathrm{Bu}$ çalışma ile depo çıkışına yakın bir depolama alanına daha hızlı hareket eden gruplar atayarak, sipariş toplama mesafesinin kısaltılabileceği belirlenmiştir. Sipariş planına göre toplanan öğelerin toplam taşıma mesafeleri öğelerin raflardaki sıralamalarına göre değişmektedir. Örneğin, 3 öğeli bir sipariş planı olduğunu varsayalım. Bu öğeler 1,2 ve 3 nolu öğeler olsun. Mevcut siparişte öğelerin sıralaması arka arkaya olduğu için toplam taşıma mesafesi kısadır. Şekil-1'de 1 nolu öğenin 8 nolu öğenin yerinde olması durumunda siparişin hazırlanması için gidilecek mesafenin çok daha fazla olacağı açıktır.

İleriki çalışmalarda matematiksel modelleme ile problemin en iyi çözümünün belirlenmesine çalışılacaktır. Senaryo bazlı farklı örnek veri setleri kullanılacaktır. Bu yeni çalışmada, sipariş sayıları, öğe sayıları, sipariş miktarları ve farklı öğe sayıları ayrı birer faktör olarak dikkate alınacaktır. Küçük, orta ve büyük ölçekte olmak üzere 3 farklı senaryo dikkate alınması planlanmaktadır. Bu senaryolar sonucunda elde edilen sonuçlar yeni çalışmada sunulacaktır.

\section{REFERANSLAR}

Accorsi, R., Baruffaldi, G., Manzini, R. (2018). Picking efficiency and stock safety: A bi-objective storage assignment policy for temperature-sensitive products. Computers \& Industrial Engineering, 115, 240-252. doi: 10.1016/j.cie.2017.11.009.

Chuang, Y., Lee, H., Lai, Y. (2012). Item-associated cluster assignment model on storage allocation problems. Computers \& Industrial Engineering, 63, 4, 1171-1177. doi: 10.1016/j.cie.2012.06.02.1.

De Koster, R., Le Duc, T., \& Roodbergen, K. J. (2007). Design and control of warehouse order picking: A literature review. European Journal of Operational Research, 182(2), 481-501. doi: 10.1016/j.ejor.2006.07.009.

Diaz, R. (2016). Using dynamic demand information and zoning for the storage of non-uniform density stock keeping units. International Journal of Production Research, 54, 8, 2487-2498. doi: 10.1080/00207543.2015.1106605.

Dijkstra, A.S., Roodbergen, K.J. (2017). Exact route-length formulas and a storage location assignment heuristic for picker-toparts warehouses. Transportation Research Part E, 102, 38-59. doi: 10.1016/j.tre.2017.04.003.

Li, J., Huang R., Dai, J. B. (2017). Joint optimisation of order batching and picker routing in the online retailer's warehouse in China. International Journal of Production Research, 55:2, 447-461. doi: 10.1080/00207543.2016.1187313.

Lin, C.-H., \& Lu, I.-Y. (1999). The procedure of determining the order picking strategies in distribution center. International Journal of Production Economics, 60-61, 301-307. doi: 10.1016/S0925-5273(98)00188-1.

Liu, C. M. (1999). Clustering techniques for stock location and order-picking in a distribution centre. Computers and Operations Research, 26 (10), 989-1002. doi: 10.1016/S0305-0548(99)00026-X.

Liu, C. M. (2004). Optimal storage layout and order picking for warehousing. International Journal of Operations Research, 1(1), $37-46$.

Şenyiğit, E., Bozdoğan, A. (2018). Tek blok tek koridor depo yerleştirme problem için yeni bir sezgisel yöntem. II. Uluslararası bilimsel ve mesleki çalışmalar kongresi bildiriler kitabı, 1, 636-642. 